\section{Diana Litmanovich Phillip M. Boiselle} Alexander A. Bankier

\title{
Reply to: CT of pulmonary emphysema: Current status, challenges, and future directions
}

Received: 22 December 2008

Accepted: 22 December 2008

Published online: 24 February 2009

(C) European Society of Radiology 2009

This reply refers to the Letter to the Editor at doi:10.1007/s00330-009-1323-8.

D. Litmanovich · P. M. Boiselle

Beth Israel Deaconess Medical

Center-Radiology,

Boston, MA, USA

Dear Sir,

We thank the author of the above letter for his interesting and pertinent remarks on our recent review article. Madani et al. [1] indeed used transverse images for their quantification of emphysema. We presume that their choice of transverse sections was determined by the attempt to embed their results in the context of their own work [2, 3] and into the context of previous sentinel articles about the CT quantification of emphysema [4, 5]. We believe that this should not preclude the analysis of truly volumetric CT data for the quantification of emphysema, and we follow the authors of the letter in encouraging future research on this interesting topic.

A. A. Bankier $(\bowtie)$

Beth Israel Deaconess Medical

Center-Radiology,

Respiratory Functional Imaging,

330 Brookline Avenue,

Boston, MA, 02215, USA

e-mail: abankier@bidmc.harvard.edu

Tel.: +1-617-6672862

Fax: +1-617-6677917

\section{References}

1. Madani A, Zanen J, de Maertelaer V, Gevenois PA (2006) Pulmonary emphysema: objective quantification at multidetector row $\mathrm{CT}$ - comparison with macroscopic and microscopic morphometry. Radiology 238:1036-1043
2. Madani A, De Maertelaer V, Zanen J, Gevenois PA (2007) Pulmonary emphysema: radiation dose and section thickness at multidetector CT quantification - comparison with macroscopic and microscopic morphometry. Radiology 243:250-257

3. Madani A, van Muylem A, de Maertelaer V, Zanen J, Gevenois PA (2008) Pulmonary emphysema: size distribution of emphysematous spaces on multidetector CT images - comparison with macroscopic and microscopic morphometry. Radiology 248:10361041
4. Gevenois PA, de Maertelaer V, De Vuyst P, Zanen J, Yernault JC (1995) Comparison of computed density and macroscopic morphometry in pulmonary emphysema. Am J Respir Crit Care Med 1995 152:653-657

5. Gevenois PA, De Vuyst P, de Maertelaer V, Zanen J, Jacobovitz D, Cosio MG, Yernault C (1996) Comparison of computed density and microscopic morphometry in pulmonary emphysema. Am J Respir Crit Care Med 154:187-192 